\title{
Spike Protein Rigid Motif shared by SARS-CoV and SARS-CoV-2 (2019-nCoV): Flexible Conformations Predicted by using Supersecondary Structure Codes
}

\author{
Hiroshi Izumi ${ }^{1}$ \\ ${ }^{1}$ National Institute of Advanced Industrial Science and Technology
}

May 5, 2020

\begin{abstract}
I compared the predicted and observed flexible conformations of SARS-CoV and SARS-CoV-2 (2019-nCoV) spike proteins by using supersecondary structure codes (SSSCs) and a comparison program of three deep-neural-network-based prediction systems (SSSCPred200, SSSCPred100, and SSSCPred). The SARS-CoV SSSC sequences predicted by the three deep-neuralnetwork-based systems well reproduced those of the Protein Data Bank (PDB) data, including the structured loops. Only one common identical motif (SSSC: SSSHSSHHHH) among all of the compared SSSC sequences, including predicted and observed ones, was found at the S2 position. This motif has an extremely rare rigid conformation. The antibody or ligand binding to the spike protein S2 of SARS-CoV near the rigid motif may also have a more accessible effect on SARS-CoV-2 than those binding to the receptor-binding motif of SARS-CoV have.
\end{abstract}

\section{Hosted file}

2019_nCoV_izumih_rev5.pdf available at https://authorea.com/users/301438/articles/431244spike-protein-rigid-motif-shared-by-sars-cov-and-sars-cov-2-2019-ncov-flexibleconformations-predicted-by-using-supersecondary-structure-codes 